\title{
JBDS guideline for the use of VRIII in medical patients - a commentary
}

\author{
JONATHAN WEBBER
}

\begin{abstract}
Variable rate intravenous insulin infusion (VRIII) - previously sliding scale insulin - is an established methodology to achieve normoglycaemia in hospital patients with severe hyperglycaemia. However there are several different sliding scales, even within the same hospital. This new guideline is designed for use by any healthcare professional responsible for the care of acutely unwell patients who present with hyperglycaemia - with or without a previous diagnosis of diabetes. It offers practical guidance on use of VRIII and patient transition to other glucose-lowering therapy on stabilisation.
\end{abstract}

Br J Diabetes Vasc Dis 2014;14:158-160

Key words: hyperglycaemia, guideline, insulin, sliding scale insulin, variable rate intravenous insulin infusion,

\section{Introduction}

For many years each hospital has had its own way, or in many cases several ways, of managing in-patients with high glucose levels. In the acutely unwell patient, the default solution is usually an intravenous insulin regime. This was often what was termed "sliding scale insulin". It was envisaged by most prescribers (normally junior doctors) that this would solve the acute problem and that they could safely leave the patient to be managed by nursing staff. A number of problems have arisen with this approach. These include the use of numerous different sliding scales (now termed VRIII) even within the same hospital; the recognition that one size does not fit all; the inappropriate use of VRIII when it was not required; failure to review the effectiveness of the VRIII regime prescribed (leading to either recurrent hypoglycaemia, or sustained hyperglycaemia); and subsequent problems with fluid balance and electrolyte disturbance. In addition, there was little consideration of when VRIII therapy should be stopped and how the transition process back on to subcutaneous insulin should be managed.

\section{The guideline}

The JBDS guideline for the use of VRIII in adult medical patients,

Address for correspondence: Dr Jonathan Webber

Diabetes Centre, University Hospital Birmingham NHS Foundation Trust,

Edgbaston, Birmingham, B15 2WB, UK

Tel: +44 (0)1213713973

E-mail: Jonathan.webber@uhb.nhs.uk

http://dx.doi.org/10.15277/bjdvd.2014.048

\author{
Abbreviations and acronyms \\ $A B C D \quad$ Association of British Clinical Diabetologists \\ BSPED British Society for Paediatric Endocrinology and Diabetes \\ DKA diabetic ketoacidosis \\ JBDS Joint British Diabetes Societies \\ VRIII variable rate intravenous insulin infusion
}

published in October 2014, is designed to improve the management of patients requiring intravenous insulin treatment. The full guidance can be accessed via the ABCD website. ${ }^{1}$ Table 1 summarises some of the key points. The guideline complements advice offered by JBDS to treat DKA in adults (September 2013)2 and advice from the BSPED for the management of DKA in people $<18$ years (November 2013). ${ }^{3}$ Other guidelines for circumstances in which intravenous insulin may be required, such as surgery, enteral feeding and myocardial infarction, are available to download from the ABCD website. ${ }^{4}$

The introduction to the guidance recognises that there is a dearth of trial evidence to guide diabetes management for the in-patient population. Effective and safe solutions that minimise the use of VRIII are still needed. One trial showed that a variable regime based on basal bolus subcutaneous insulin could control acute hyperglycaemia better than alternative subcutaneous regimes, but this was not compared with VRIII. ${ }^{5}$ It is also thought that significant expertise and support is required to introduce such a protocol to hospitals. At present this level of support is lacking in many UK hospital trusts. It is envisaged that most patients put onto VRIII will be referred to the diabetes team for advice on ongoing management, and even this has proved difficult to implement.

The JBDS guideline for the use of VRIII is therefore aimed at improving the management of those patients who require this therapy. I suspect the extensive background and references will only be read by diabetes teams, but it is the clear and pragmatic guidance that will hopefully be taken on board by all those involved in managing patients with diabetes whilst they are in hospital. The key points are around the indications for the use of a VRIII in medical patients and the quick reference tool in Appendix 4 of the guidance. VRIII should be used:

- in patients with recurrent vomiting (unless associated with DKA in which case the relevant JBDS guideline for DKA should be used);

- those who are nil by mouth and missing more than one meal; and

- those with severe illness who need to achieve good glycaemic control (e.g. sepsis). 
Table 1 Key points from the guidance

\begin{tabular}{|c|c|}
\hline When to use VRIII & $\begin{array}{l}\text { - } \quad \text { NBM type } 1 \text { diabetes }>1 \text { missed meal } \\
\text { - } \quad \text { Type } 1 \text { diabetes with recurrent vomiting (exclude DKA) } \\
\text { - Type } 1 \text { or } 2 \text { diabetes and severe illness with need to achieve good glycaemic control e.g. sepsis }\end{array}$ \\
\hline Targets & $\begin{array}{l}\text { - } \quad \text { BG in range } 6.0-10.0 \mathrm{mmol} / \mathrm{L}(4.0-12.0 \mathrm{mmol} / \mathrm{L} \text { acceptable) } \\
\text { - } \quad \text { Avoid hypoglycaemia }(\mathrm{CBG}<4.0 \mathrm{mmol} / \mathrm{L}) \\
\text { - } \quad \text { Limit use to }<24 \text { hours where possible } \\
\text { - } \quad \text { Try to avoid using in those patients able to eat and drink }\end{array}$ \\
\hline $\begin{array}{l}\text { How to manage hypoglycaemia whilst } \\
\text { on VRIII }\end{array}$ & $\begin{array}{l}\text { For CBG < } 4.0 \mathrm{mmol} / \mathrm{L} \text { i.e. hypoglycaemia } \\
\text { - } \quad \text { Stop the VRIII and treat the hypo as per local hypo guidelines } \\
\text { - } \quad \text { NOTE the VRIII should generally not be stopped for }>20 \text { minutes } \\
\text { - STEP DOWN to the next scale when the VRIII is restarted - if you are already using the lowest pre } \\
\text { prescribed scale, then use the customised section to downgrade further } \\
\text { - } \\
\text { Review again within } 6 \text { hours }\end{array}$ \\
\hline $\begin{array}{l}\text { How to manage hyperglycaemia whilst } \\
\text { on VRIII }\end{array}$ & $\begin{array}{l}\text { For CBGs persistently above } 12.0 \mathrm{mmol} / \mathrm{L} \text { and NOT falling } \\
\text { - } \quad \text { Upgrade the scale and review again within } 6 \text { hours } \\
\text { - } \quad \text { Check ketones } 4 \text { hourly if have type } 1 \text { diabetes, at least once if type } 2 \text { diabetes }\end{array}$ \\
\hline Concurrent fluids & $\begin{array}{l}\text { - } 1 \text { litre } 0.45 \% \mathrm{NaCl} \text { with } 5 \% \text { glucose and } 0.3 \% \mathrm{KCl}(40 \mathrm{mmol} / \mathrm{L}) \text { at } 125 \mathrm{ml} / \mathrm{hr} \\
\text { If not available use the following; } \\
\text { - } 1 \text { litre } 5 \% \text { glucose with } 0.3 \% \mathrm{KCl}(40 \mathrm{mmol} / \mathrm{L}) \text { at } 125 \mathrm{ml} / \mathrm{hr} \\
\text { - In dehydrated patients concurrent } 0.9 \% \mathrm{NaCl} \text { may be required } \\
\text { In patients with severe cardiac or renal impairment } 10 \% \text { dextrose may be required to avoid fluid } \\
\text { overload }\end{array}$ \\
\hline Monitoring & $\begin{array}{l}\text { - } \quad \text { CBGs must be monitored hourly whilst the VRIII is in use } \\
\text { - } \quad \text { Check electrolytes daily whilst on VRIII }\end{array}$ \\
\hline Management of usual diabetes medications & - $\quad$ Continue usual basal insulin alongside VRIII \\
\hline When to contact the diabetes team & $\begin{array}{l}\text { - If you are unable to achieve CBGs within target range } \\
\text { - If your patient requires a VRIII for }>24 \text { hours } \\
\text { - If diabetes control was suboptimal prior to admission (i.e. recent pre admission } \mathrm{HbA}_{1 \mathrm{c}} \\
>59 \mathrm{mmol} / \mathrm{mol} \text { ) }\end{array}$ \\
\hline $\begin{array}{l}\text { Transfer to usual diabetes treatment on } \\
\text { discontinuation of VRIII }\end{array}$ & $\begin{array}{l}\text { - } \quad \text { Ensure the patient is able to eat and drink } \\
\text { - } \quad \text { VRIII discontinuation takes place at a mealtime with usual diabetes medications given } \\
\text { Check CBG one hour after discontinuing the VRIII and } 4 \text { hourly for the next } 24 \text { hours to ensure } \\
\text { there is no rebound hyperglycaemia }\end{array}$ \\
\hline
\end{tabular}

Suggested insulin infusion rates are provided together with details concerning continuation of basal insulin in most cases and the transition phase from VRIII to usual diabetes therapy. Within the document there is also advice on setting up a VRIII, managing hypoglycaemia that occurs whilst on VRIII, when to check capillary blood ketones and the choice of concurrent intravenous fluids. As the authors recognise, guidance on the type of fluid remains a contentious issue; their proposed solution $(0.45 \% \mathrm{NaCl}$ with $5 \%$ glucose and $0.3 \% \mathrm{KCl})$ is not widely available (although it has also been championed in the diabetes and surgery JBDS guidance ${ }^{6}$ ). The emphasis is at least to ensure that some substrate is going in to reduce the risk of hypoglycaemia whilst on VRIII. How much substrate and whether additional fluids are required will be determined by other patient variables (e.g. risk of fluid overload, renal function, liver function).

Whilst this guidance should help improve in-patient diabetes care, there are several obstacles when it comes to implementa- tion. Education of health professionals (nurses and doctors) who administer and prescribe VRIII is needed so that they understand the rationale behind the advice given. Specialist time and support will be required both for this and for input to those patients where VRIII is not effective. I hope that this document serves to upskill non-specialists so that they are able to do the basics well and not become over-reliant on specialist diabetes teams. There remains the challenge of finding technology that allows good glycaemic control and further reduces the risk of hypoglycaemia in this vulnerable in-patient population.

\section{Conflict of interest None \\ Funding sources None}

\section{References}

1. Association of British Clinical Diabetologists. Joint British Diabetes Societies for Inpatient Care. The use of variable rate intravenous insulin infusion (VRIII) in medical patients. October 2014. http://www. diabetol- 
ogists-abcd.org.uk/JBDS/JBDS.htm (Accessed October 2014).

2. Joint British Diabetes Societies for Inpatient Care Group. The management of diabetic ketoacidosis in adults. March 2010. http://www.diabetologists-abcd.org.uk/JBDS_DKA_Management.pdf (Accessed October 2014).

3. British Society for Paediatric Endocrinology and Diabetes Recommended DKA Guidelines 2009 (minor review 2013). http://www.bsped.org.uk/ clinical/docs/DKAGuideline.pdf (Accessed October 2014).
4. Access to guidelines for situations in which intravenous insulin may be required. http://www. diabetologists-abcd.org.uk/JBDS/JBDS.htm (Accessed October 2014).

5. Umpierrez G, Smiley D, Zisman A, Prieto L. Randomized study of basalbolus insulin therapy in the inpatient management of patients with type 2 diabetes (RABBIT 2 trial). Diabetes Care 2007;30:2181-6. http://dx.doi.org/10.2337/dc07-0295

\title{
RECRUITING NOW
}

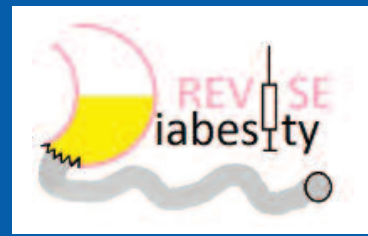

\section{Do you have patients with type 2 diabetes and obesity needing better control, despite previous liraglutide use?}

REVISE-Diabesity is a randomised controlled trial which offers the real chance of improved glycaemic control and reduced weight to enrolled participants, who will be randomised to: 1) Liraglutide 1.8mg, 2) Endobarrier, 3) Endobarrier + liraglutide

Endobarrier is an endosopically inserted duodenal-jejunal bypass liner which early studies suggest might lead to considerable weight loss and improved glycaemic control

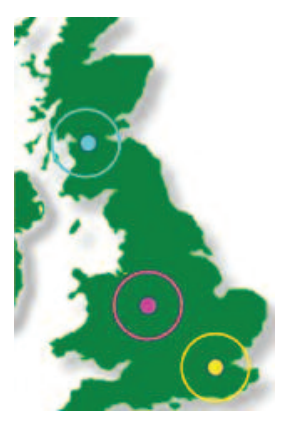

\author{
To refer patients (Glasgow/ Birmingham / London) \\ please contact: \\ Dr Piya Sen Gupta, \\ ABCD Research Fellow \\ Email: revise.diabesity@nhs.net \\ Mobile: 07866319487
}

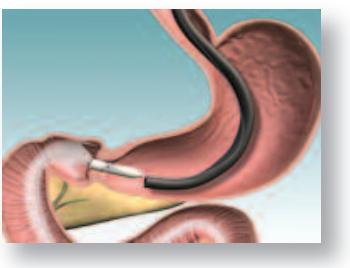

Please see the study website (includes selection criteria):

http://www.diabetologists-abcd.org.uk/research/endobarrier_study.htm

ISRCTN00151053, NCT02055014 